ФТИ-2020

\title{
AN AUTOMATED CLASSIFIER AND COUNTER FOR MICROBIOLOGICAL OBJECTS
}

\author{
Izmozherov I.B. ${ }^{1}$, Smirnov A.A. ${ }^{1}$
}

1) Ural Federal University named after the first President of Russia B.N. Yeltsin E-mail: mamahalyava@outlook.com

An attempt to create an automated classifier and counter for microbiological objects based on neural network.

Many scientific works rely on analysis of images of microbiological objects. it can be object count, object classification, shape and color analysis etc. Such analysis always is time consuming and there is also a window for errors. Threrefore this process was from its beggining a target for numerous attempts of automation.

Most successfull tries are based on different segmentation methods [1]. All mentioned approaches are using deterministic calculations. Aim of this work is to bring another kind of image segmentation to this task - neural networks. To successfully implement to image segmentation a set of examples is required. Size of such set should be at least no less than several hundreds of images. So for this purpose photographs of irradiated yeast were chosen mainly because it is easy to segment them manually with enough accuracy. A secondary task was to make an attempt to distinguish life cell from the dead ones together with segmentation.

All calculation are done using Google Colaboratory as a computational background.

1. Д.М. Мурашов. Труды МФТИ, 1 (1), 80 - 89 (2009). 